\title{
Structural, Magnetic, Optical Properties and Photocatalytic Activity of Nanocrystalline Cobalt Ferrite Prepared by Three Different Methods
}

\author{
Samah Samy Selima ${ }^{1, *}{ }^{\mathbb{D}}$, Wafaa Abdallah Bayoumy ${ }^{1}$, Mohamed Khairy ${ }^{1,2}{ }^{\mathbb{D}}$, Mahmoud Ahmed Mousa ${ }^{1}$ \\ 1 Chemistry Department, Faculty of Science, Benha University, Benha, Egypt \\ 2 Chemistry Department, College of Science, Imam Mohammad Ibn Saud Islamic University, Riyadh, KSA \\ * Correspondence: samah_selima@yahoo.com;
}

Scopus Author ID 57205210744

Received: 10.03.2021; Revised: 12.04.2021; Accepted: 15.04.2021; Published: 27.04.2021

\begin{abstract}
Cobalt ferrite $\left(\mathrm{CoFe}_{2} \mathrm{O}_{4}\right)$ is an interesting material due to its rich physical properties. In order to study the influence of synthetic methods on the crystalline and morphological structure, optical and magnetic properties of the $\mathrm{CoFe}_{2} \mathrm{O}_{4}$, we synthesized here the $\mathrm{CoFe}_{2} \mathrm{O}_{4}$ by three different methods, including the chemical co-precipitation method, sol-gel method, and ceramic method. The resulting powders were characterized by different analyses: XRD, SEM, TEM, BET, FTIR, UV-Vis, PL, XPS, and surface acidity. The characterization results showed a significant variation in the structural, particle size, surface area, and optical properties of pure cobalt ferrite with changing the synthetic method. Both XRD and FTIR analyses confirm the formation of the cubic spinel phase, where the crystallite size changes from 21 to $36 \mathrm{~nm}$. XPS analyses demonstrated the effect of the synthetic method on the cation distribution at the tetrahedral and octahedral sites in the spinel ferrite lattice. The magnetic properties of the prepared samples were studied at room temperature using the vibrating sample magnetometer (VSM) and found to be strongly dependent on the synthetic method and showed either ferromagnetic or super-paramagnetic character. The cobalt ferrite samples showed high photocatalytic activity against Basic Red 18 (BR 18) dye under visible light irradiation. The effects of particle size, surface areas, and morphology on the photocatalytic activity were discussed and the positive holes are suggested to be the major active species of the dye dissociation.
\end{abstract}

Keywords: $\mathrm{CoFe}_{2} \mathrm{O}_{4}$; magnetic properties; optical properties; photocatalytic activity; water treatment.

(C) 2021 by the authors. This article is an open-access article distributed under the terms and conditions of the Creative Commons Attribution (CC BY) license (https://creativecommons.org/licenses/by/4.0/).

\section{Introduction}

Recently, magnetic nanoparticles have drawn an excessive research arrangement due to their characteristic properties and their scientific, technological uses. Ferrite spinels consider as the most important class of these materials. The spinel structure exhibits a general formula (A) $\left[\mathrm{B}_{2}\right] \mathrm{O}_{4}$ crystallizes in a face-centered cubic structure, with two lattice types for cation distributions of $\mathrm{A}$ and $\mathrm{B}$ sites in the tetrahedral and octahedral organization, respectively. The physical properties of ferrite spinel are linked to the cation distribution over the tetrahedral sites A (8a) and octahedral sites B (16d) of the structure. The spinel structure is more complex in practice because molecules do not always correspond fully to a normal or inverse structure. Hence, an inversion parameter, $d$, defined by $0<d<1$ is introduced [1]. Cobalt ferrite is one of the most appropriate spinel ferrites with distinctive properties such as strong spin-orbit coupling, high coercivity, high Curie temperature, high magnetocrystalline anisotropy, 
distinguished mechanical and chemical stability [2-7]. Generally, cobalt ferrite exhibits a partially inverse spinel structure in which both sites (A and $\mathrm{B}$ ) hold a fraction of $\mathrm{Co}^{2+}$ and $\mathrm{Fe}^{3+}$ cations. It shows the formula of $\left(\mathrm{Co}^{2+}{ }_{1-\delta} \mathrm{Fe}^{3+}{ }_{\delta}\right)_{\mathrm{A}}\left[\mathrm{Co}^{2+}{ }_{\delta} \mathrm{Fe}^{3+}{ }_{2-\delta}\right]_{\mathrm{B}} \mathrm{O}_{4}$, where $\delta$ is a fraction of tetrahedral sites occupied by $\mathrm{Fe}^{3+}$ ions, which is known as the degree of inversion. The degree of inversion is sensitive to numerous parameters such as the microstructure and synthesis process. This work is designed to prepare $\mathrm{CoFe}_{2} \mathrm{O}_{4}$ with three different methods (coprecipitation, ceramic, and sol-gel) and investigate how the change in each cation distribution, particle size, and surface area affect the optical and magnetic properties, which ultimately determine the magnetic and photocatalytic applications.

\section{Materials and Methods}

\subsection{Materials.}

All chemicals were reagent grade and utilized without further purification. Cobalt (11) nitrate (Hexahydrate) $\left[\mathrm{Co}\left(\mathrm{NO}_{3}\right)_{2} .6 \mathrm{H}_{2} \mathrm{O}\right]$ was acquired from SD Finchem Limited, Mumbai 400 030. Ferric nitrate $\left[\mathrm{Fe}\left(\mathrm{NO}_{3}\right)_{3} .9 \mathrm{H}_{2} \mathrm{O}\right]$ was obtained from LOBA CHEMIE PVT.LTD. Cobalt (11) acetate $\left[\left(\mathrm{CH}_{3} \mathrm{COO}\right)_{2} \mathrm{Co} .4 \mathrm{H}_{2} \mathrm{O}\right]$ was purchased from Fluka, Garantie, Switzerland. Cobalt sulfate $\mathrm{CoSO}_{4} .7 \mathrm{H}_{2} \mathrm{O}$ was prepared from the reaction of $\mathrm{H}_{2} \mathrm{SO}_{4}$ with $\mathrm{CoCl}_{2}$. Bidistilled water was utilized in all the experiments.

\subsection{Synthesis of $\mathrm{CoFe}_{2} \mathrm{O}_{4}$ Samples.}

$\mathrm{CoFe}_{2} \mathrm{O}_{4}$ nanoparticles were prepared by three different methods.

\subsubsection{Ceramic method.}

A mixture of $\mathrm{CoSO}_{4} .7 \mathrm{H}_{2} \mathrm{O}, \mathrm{Fe}\left(\mathrm{NO}_{3}\right)_{3} .9 \mathrm{H}_{2} \mathrm{O}, \mathrm{NaOH}$, and $\mathrm{NaCl}$ in the molar ratio of 1 : 2: 8: 10 were pulverized together in an agate mortar for about $60 \mathrm{~min}$., followed by calcination at $700^{\circ} \mathrm{C}$ for two hours. The obtained product was crushed and well washed with bidistilled water and dried at $95^{\circ} \mathrm{C}$ for one hour and heated to $700^{\circ} \mathrm{C}$ with a heating rate of $5^{\circ} \mathrm{C} / \mathrm{min}$. The sample was symbolized as $\mathrm{CoFe}_{\text {s. }}$.

\subsubsection{Co-precipitation method.}

Cobalt and iron nitrate, in a molar ratio of 1:2, were dissolved in bidistilled water. Urea was then added to the heated solution at $90^{\circ} \mathrm{C}$ with stirring. The precipitate obtained was filtered, well washed with bidistilled water, and dried at $95^{\circ} \mathrm{C}$ for 12 hours. Finally, the powder acquired was calcined up to $700^{\circ} \mathrm{C}$ with a heating rate of $5^{\circ} \mathrm{C} / \mathrm{min}$. The sample was denoted as $\mathrm{CoFe}_{\mathrm{p}}$.

\subsubsection{Sol-gel method.}

A mixture of $2.91 \mathrm{~g}$ of $\left[\mathrm{Co}\left(\mathrm{NO}_{3}\right)_{2} .6 \mathrm{H}_{2} \mathrm{O}\right], 8.08 \mathrm{~g}$ of $\left[\mathrm{Fe}\left(\mathrm{NO}_{3}\right)_{3} .9 \mathrm{H}_{2} \mathrm{O}\right.$ ], and $10 \mathrm{~g}$ of citric acids were dissolved in bidistilled water with stirring at $85^{\circ} \mathrm{C}$ to get gel phase. The gel gained was then dried in an oven at $100^{\circ} \mathrm{C}$ for 12 hours. Finally, the powder obtained was calcined up to $700^{\circ} \mathrm{C}$ with a heating rate of $5^{\circ} \mathrm{C} / \mathrm{min}$. The sample was symbolized as $\mathrm{CoFe}$. 


\subsection{Characterization methods.}

XRD analysis was performed on a Philips X' Pert Pro Super diffractometer with $\mathrm{Cu} \mathrm{K \alpha}$ radiation $(\lambda=1.54 \AA)$. Electron microscope analysis was done by SEM and TEM electron microscopy model JEOL JEM-100CXII and JEOL-2010, respectively. The FT-IR spectra of the specimens were obtained by employing a Brucker-FT-IR in the range of $4000-400 \mathrm{~cm}^{-1}$. A U-1000 laser Raman Spectrometer with $514.5 \mathrm{~nm}$ line of an ArC laser was used to determine Raman spectra. Optical absorption was measured by employing Cary 5G equipment at wavelengths ranging from 200 to $1000 \mathrm{~nm}$. The photoluminescence (PL) studies were made using a $225 \mathrm{~nm}$ excitation wavelength source. Traditional surface area and textural surface properties were studied using the BET - $\mathrm{N}_{2}$ gas adsorption technique. The electron binding energies for the elements were determined using a PHI-5702 multifunctional spectrometer with AlK $\alpha$ radiation (XPS). The magnetic properties of the prepared samples were studied using the vibrating sample magnetometer model (VSM-9600M-1, USA) in a maximum applied field of $10 \mathrm{kOe}$.

A programable ammonia desorption technique (TPD- $\mathrm{NH}_{3}$ ) was used to determine the type and the amount of acidity in the studied samples. This is performed in a reactor filled with $0.4 \mathrm{~g}$ of the sample, which was previously activated at $250{ }^{\circ} \mathrm{C}$ for 3 hours with $\mathrm{N}_{2}$ flow. The sample was then permitted to expose to $\mathrm{NH}_{3}$ at room temperature for one hour. The overflow of $\mathrm{NH}_{3}$ was swill out of the reactor with $\mathrm{N}_{2}$ flow. The temperature was then elevated linearly at a rate of $10{ }^{\circ} \mathrm{C} / \mathrm{min}$ to liberate $\mathrm{NH}_{3}$ gas from the sample at a temperature interval of $100{ }^{\circ} \mathrm{C}$ up to $500{ }^{\circ} \mathrm{C}$. The liberated $\mathrm{NH}_{3}$ is allowed to flow through a known large amount of $\mathrm{H}_{2} \mathrm{SO}_{4}$ solution. Finally, the amount of acid was determined by back titration with $\mathrm{NaOH}$ solution using M.O. indicator.

\subsection{Photocatalytic study.}

Basic Red 18 (BR 18) dye was selected as an ideal system for a catalytic reaction because of its intense color in an aqueous medium and low biodegradability due to the existence of benzene rings. The photocatalytic degradation of Basic Red 18 (BR 18) dye over ferrite nanoparticles was performed in a photoreactor with a total capacity of $0.5 \mathrm{~L}$. The illumination source was a UV-C lamp (200-980 nm, $9 \mathrm{~W}$, Philips) put in the internal quartz tube of the photoreactor. The impact of ferrite dosage on Basic Red 18 (BR 18) dye oxidation was examined using a dose of $0-0.05 \mathrm{~g} / \mathrm{l}$. The photocatalytic study was investigated at a $\mathrm{pH}$ range of 2-9 and initial dye concentration in the range of 50-200 ppm. The solution $\mathrm{pH}$ was regulated using $\mathrm{NaOH}$ or $\mathrm{HCl}$. Specimens were removed from the arrangement at specific periods and centrifuged, and the concentration in the supernatant dye solution was then analyzed using UVvis Spectrophotometer (a Cary 5G equipment).

\section{Results and Discussion}

\subsection{Characterizations.}

XRD patterns of the prepared $\mathrm{CoFe}_{2} \mathrm{O}_{4}$ ferrites are shown in Figure 1. All the ferrite samples showed diffraction peaks at $2 \theta$ values $31.6^{\circ}, 37.0^{\circ}, 44.1^{\circ}, 55.4^{\circ}, 59.1^{\circ}$ and $65.1^{\circ}$ attributed to the reflection planes of (220), (311), (400), (422), (511) and (440), respectively, of the spinel crystal structure (JCPDS 22-1086). No other peaks are observed for all specimens indicating the purity of the ferrites. There is a slight shift of (311) peak towards lower angle 
side in the order $\mathrm{CoFe}_{\mathrm{s}}>\mathrm{CoFe}_{\mathrm{p}}>\mathrm{CoFe}$. The average lattice constant (a) for the (311) plane was determined using equation (1) [8], and the results obtained are listed in Table 1.

$$
a=\sqrt{h^{2}+k^{2}+l^{2}} / 2 \sin \theta
$$

where " $h \mathrm{kl}$ " are miller indices. It is noted that the lattice constant follows the order: $\mathrm{CoFe}_{\mathrm{s}}>$ $\mathrm{CoFe}_{\mathrm{p}}>\mathrm{CoFe}_{\mathrm{g}}$. This may be attributed to a certain number of $\mathrm{Co}^{2+}$ ions $(0.78 \AA)$ transfer from octahedral sites, accompanied by the opposite migration of an equivalent number of $\mathrm{Fe}^{3+}$ ions $(0.645 \AA)$ from tetrahedral to octahedral sites to relax the compressive strain. The average crystallite sizes ( $\left.D_{X R D}\right)$ of the investigated samples were calculated (based on 3 different peaks) from the widening of reflection peaks using the Scherrer formula [7]:

$$
D_{X R D}=0.9 \lambda / \beta \cos \theta
$$

where $\lambda$ is the $\mathrm{X}$-ray wavelength, and $\beta$ is the half peak width of the diffraction peak in radiant. The results are listed in Table 1 and found to lie in the range of $21-33 \mathrm{~nm}$. The average X-ray density $\left(\rho_{x}\right)$ of the cobalt ferrite nanoparticles was determined using the following equation:

$$
\rho_{x}=8 M / N a^{3}
$$

Where $M$ is the molecular weight of cobalt ferrite, $N$ is Avogadro's number. The results are also listed in Table 1.

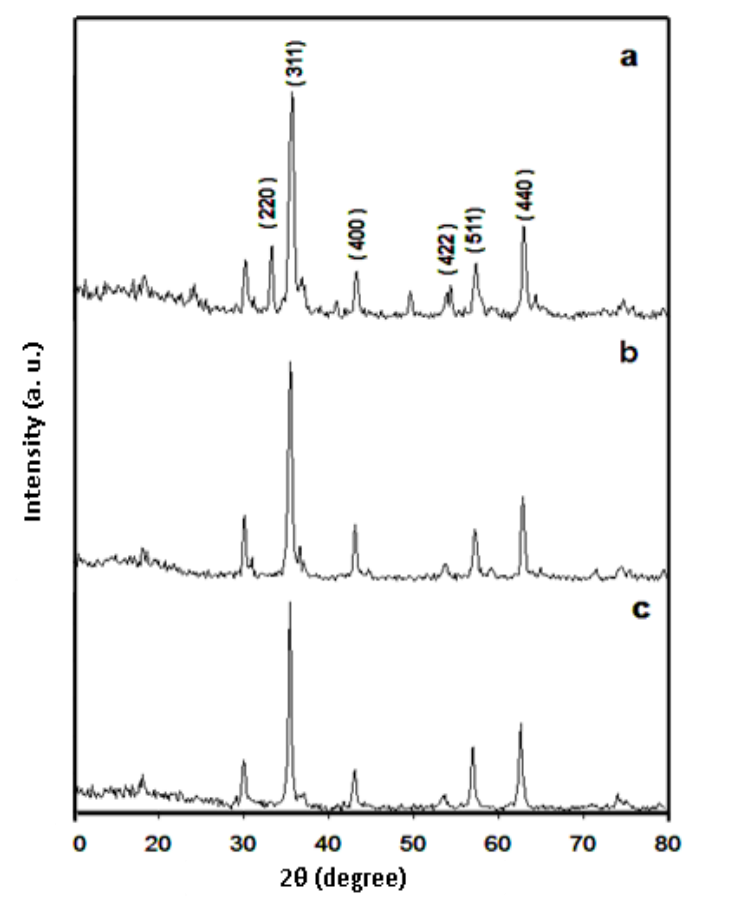

Figure 1. XRD of $\mathrm{CoFe}_{2} \mathrm{O}_{4}$ samples (a) $\mathrm{CoFe}_{\mathrm{s}}$; (b) $\mathrm{CoFe}_{\mathrm{g}}$ and (c) $\mathrm{CoFe}_{\mathrm{p}}$

Table 1. Lattice constant, density, particle size values, and FT-IR data of the studied $\mathrm{CoFe}_{2} \mathrm{O}_{4}$ samples.

\begin{tabular}{c|c|c|c|c|c|c|c|c} 
Sample & $\begin{array}{c}\text { Lattice } \\
\text { constant( }(\mathbf{A})\end{array}$ & $\begin{array}{c}\text { X-ray } \\
\text { density } \\
\left(\mathbf{g} / \mathbf{c m}^{\mathbf{3}}\right)\end{array}$ & $\begin{array}{c}\text { XRD- } \\
\text { particle } \\
\text { size } \\
(\mathbf{n m})\end{array}$ & $\begin{array}{c}\text { TEM- } \\
\text { Particle } \\
\text { size } \\
(\mathbf{n m})\end{array}$ & $\begin{array}{c}\text { Tetrahedral } \\
\text { vibration } \\
\mathbf{v}_{1}\left(\mathbf{c m}^{-1}\right)\end{array}$ & $\begin{array}{c}\text { Octahedral } \\
\text { Vibration } \\
\mathbf{V}_{2}\left(\mathbf{c m}^{-1}\right)\end{array}$ & $\begin{array}{c}\text { OH- } \\
\text { group }\end{array}$ & $\begin{array}{c}\mathbf{\delta H - O - H} \\
\text { bonding }\end{array}$ \\
\hline $\mathrm{CoFe}_{\mathrm{g}}$ & 8.387 & 5.282 & 21 & 23 & 563 & 402 & 3428 & 1640 \\
\hline $\mathrm{CoFe}_{\mathrm{p}}$ & 8.392 & 5.267 & 31 & 28 & 579 & 413 & 3432 & 1625 \\
\hline $\mathrm{CoFe}_{\mathrm{s}}$ & 8.412 & 5.235 & 36 & 39 & 581 & 428 & 3439 & 1635
\end{tabular}


The formation of the $\mathrm{CoFe}_{2} \mathrm{O}_{4}$ spinel structure was also supported by infrared spectra shown in Figure 2. The spectra of all samples demonstrate two specific bands for spinel structure, $v_{1}$ in the range $581-563 \mathrm{~cm}^{-1}$, relates to $\mathrm{M}_{\mathrm{tetr}}-\mathrm{O}$ vibration at the tetrahedral site, and $v_{2}$ in the range $428-402 \mathrm{~cm}^{-1}$ attributed to Mocta $-\mathrm{O}$ vibration at the octahedral sites [9-11]. The mean feature bands observed are recorded in Table 1 . The variation in the band positions is due to the difference in the metal-O distances for the octahedral and tetrahedral complexes referring to a change in cation distribution in the spinel structure by changing the preparation method. These results strongly support the results of XRD data. The broad bands focused at $1640-1625 \mathrm{~cm}^{-1}$ are appointed to the $\delta \mathrm{H}-\mathrm{O}-\mathrm{H}$ bonding mode of the adsorbed water [12].

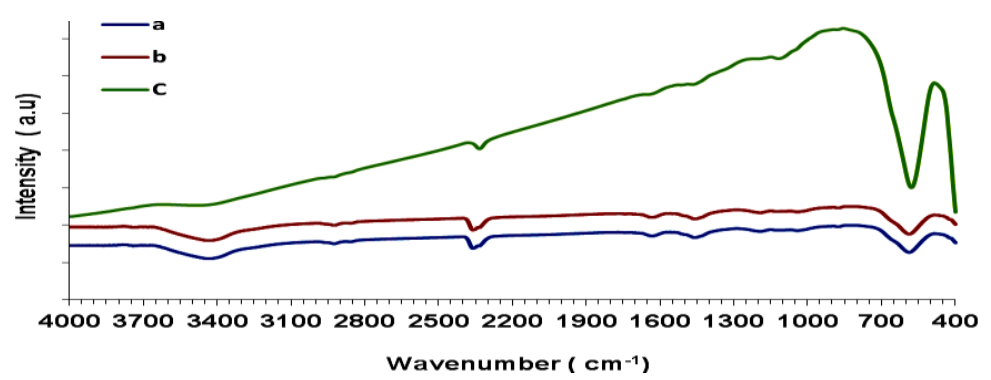

Figure 2. FT-IR of $\mathrm{CoFe}_{2} \mathrm{O}_{4}$ samples (a) $\mathrm{CoFe}_{\mathrm{p}}$, (b) $\mathrm{CoFe}_{\mathrm{s}}$; (c) $\mathrm{CoFe}_{\mathrm{g}}$.

The SEM and TEM micrographs of the as-synthesized $\mathrm{CoFe}_{2} \mathrm{O}_{4}$ particles are given in Figure 3 (A and B). As seen, depending on the preparation method, the nanoparticles have been developed in different orders and clusters.

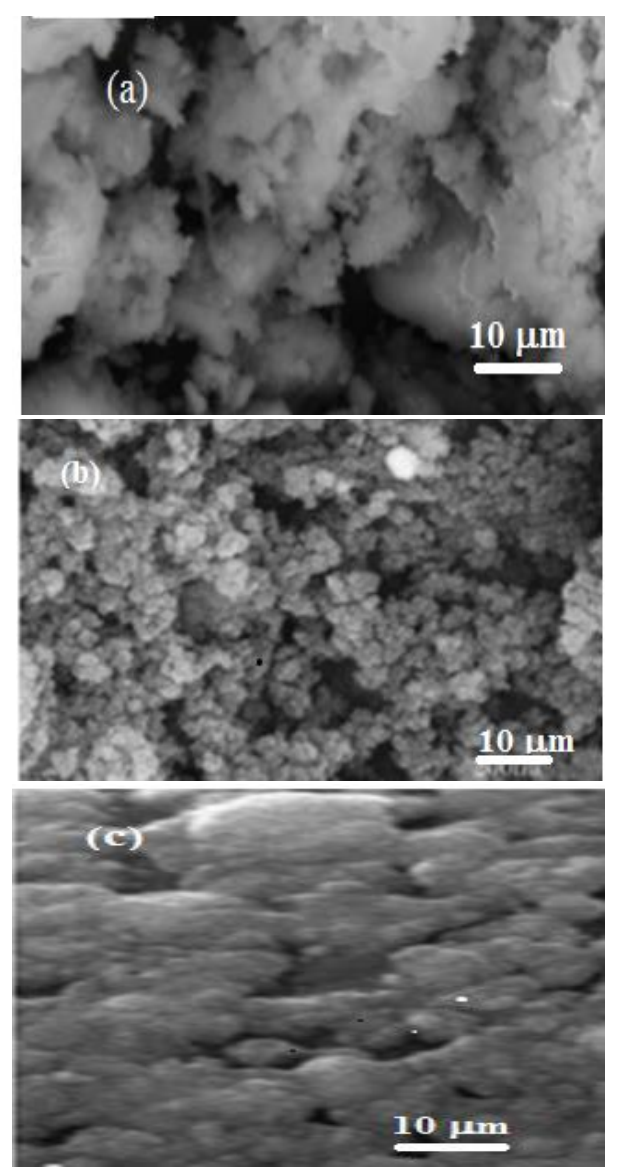

(A)
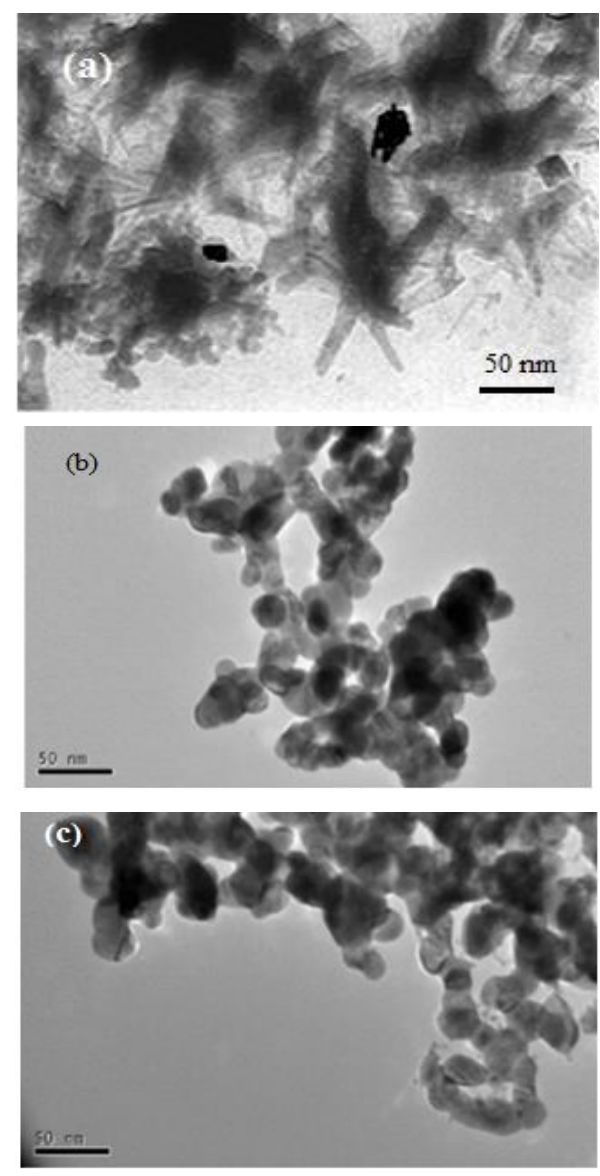

(B)

Figure 3. (A) SEM and (B) TEM of (a) $\mathrm{CoFe}_{\mathrm{s}}$; (b) $\mathrm{CoFe}_{\mathrm{p}}$ and (c) $\mathrm{CoFe}_{\mathrm{g}}$. 
SEM and TEM images of $\mathrm{CoFe}_{\mathrm{s}}$ show morphology nanoparticles predominated by nanorods structure. The other cobalt ferrite specimens, $\mathrm{CoFe}_{\mathrm{p}}$ and $\mathrm{CoFe}_{\mathrm{g}}$, demonstrates aggregated spherical particles besides particles with polygon morphologies. The variation in the morphology of the NPS shown in Figure 2.b denotes that the crystal growth of $\mathrm{CoFe}_{2} \mathrm{O}_{4}$ depends largely on the preparation method. The nanoparticle sizes were obtained using histograms of 100 particles observed in the TEM image are listed in Table 1 . The slight contrast found in the results of XRD and TEM is due to the different handles of the two tools. TEM analysis offers a number-average size distribution. XRD manifests a volume-averaged median size. In XRD, the correctness of Scherrer's formula is influenced by numerous variables, for example, diffraction line width and surface tension. Thus, Scherrer's equation might cause particular errors in determining the fixed value of the crystallite size [7].

XPS results of the $\mathrm{CoFe}_{2} \mathrm{O}_{4}$ samples are given in Figure 4, where binding energy (B.E.) ranges from 0 to $1200 \mathrm{eV}$. The spectra show that the samples contain only the main elements: $\mathrm{Fe}, \mathrm{Co}$, and $\mathrm{O}$, besides the contaminated $\mathrm{C}$ element coming from the environment. The binding energy (B.E.) values obtained attached well with the literature data for $\mathrm{CoFe}_{2} \mathrm{O}_{4}$, Table 2, [13] proving that pure ferrite had been produced.
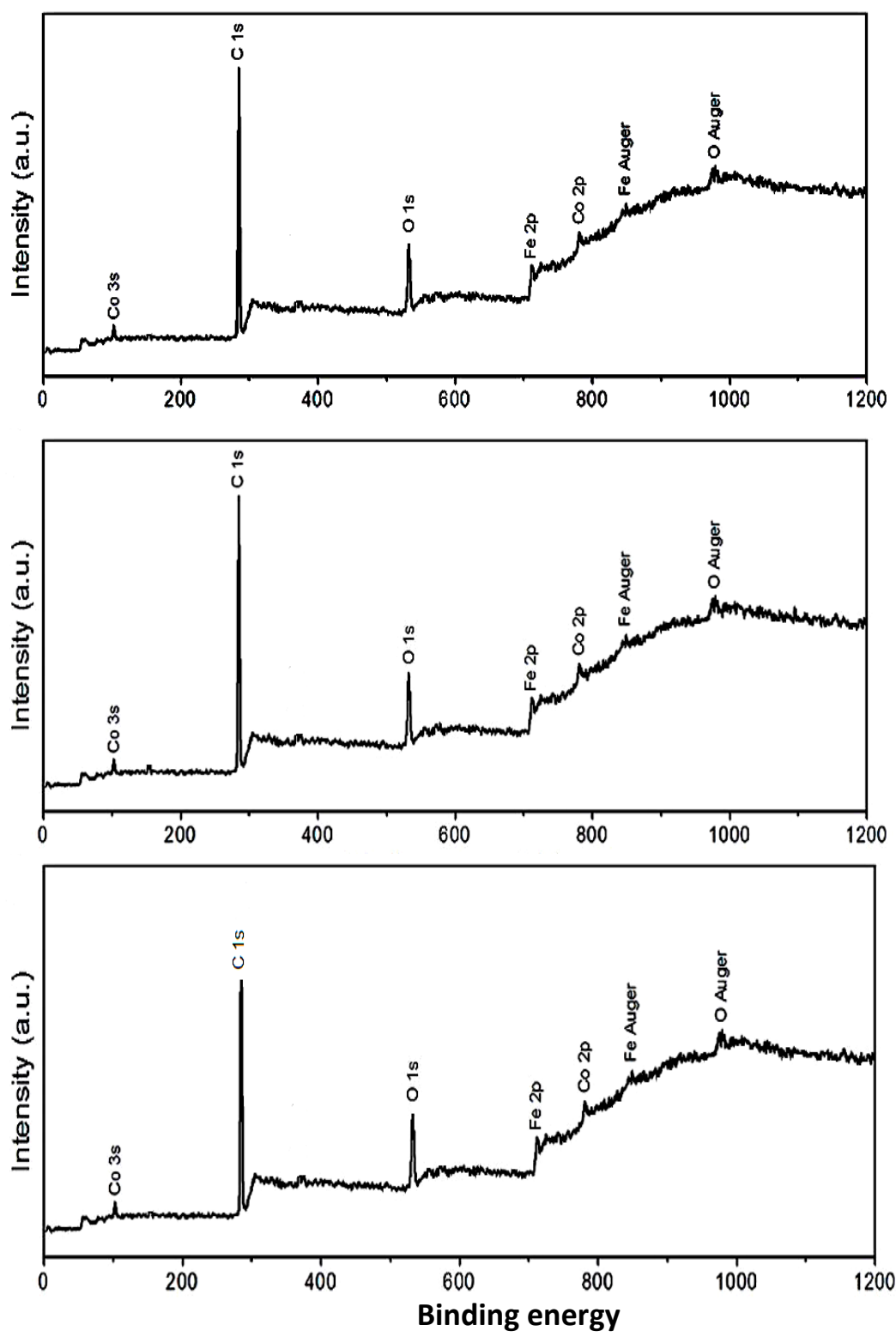

Figure 4. XPS of (a) $\mathrm{CoFe}_{s} ;$ (b) $\mathrm{CoFe}_{\mathrm{p}} ;$ (c) $\mathrm{CoFe}_{\mathrm{g}}$. 

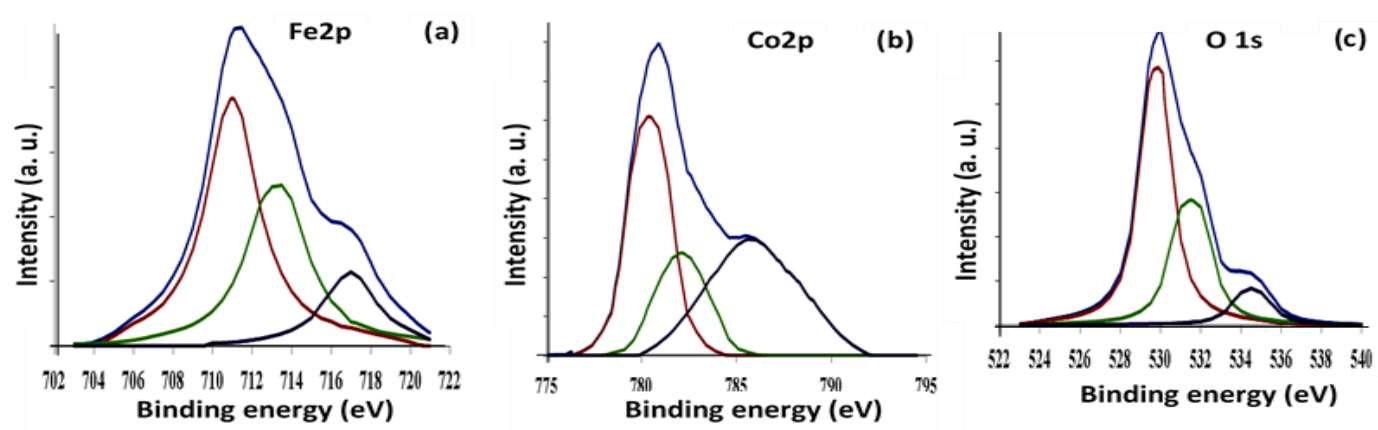

Figure 5. High-resolution XPS of $\mathrm{CoFe}_{\mathrm{g}}$ sample.

Table 2. XPS results of the investigated $\mathrm{CoFe}_{2} \mathrm{O}_{4}$ samples.

\begin{tabular}{|c|c|c|c|c|c|}
\hline Sample & Spectrum & $\mathrm{BE}(\mathrm{eV})$ & Assignment & Atomic \% & $\begin{array}{c}\text { Particle } \\
\text { Size }(\mathbf{n m}) \\
\end{array}$ \\
\hline \multirow{9}{*}{$\mathrm{CoFe}_{\mathrm{s}}$} & \multirow{3}{*}{ Co $2 p^{3 / 2}$} & 780.3 & Octahedral $\mathrm{Co}^{2+}$ & 48 & \multirow{9}{*}{36} \\
\hline & & 782.1 & tetrahedral $\mathrm{Co}^{2+}$ & 52 & \\
\hline & & 785 & satellite peak of $\mathrm{Co}^{2+}$ & - & \\
\hline & \multirow{3}{*}{$\mathrm{Fe} 2 \mathrm{p}^{3 / 2}$} & 711 & octahedral Fe $\mathrm{Fe}^{3+}$ & 76 & \\
\hline & & 713.5 & tetrahedral $\mathrm{Fe}^{3+}$ & 24 & \\
\hline & & 717 & Satellite peak $\mathrm{Fe}^{3+}$ & - & \\
\hline & \multirow{3}{*}{$\mathrm{O} 1 \mathrm{~s}$} & 529.85 & $\mathrm{CoFe}_{2} \mathrm{O}$ & 73 & \\
\hline & & 531.5 & $\mathrm{CoFe}_{2} \mathrm{O}_{4}$ & 16 & \\
\hline & & 534 & Artifact & 11 & \\
\hline \multirow{9}{*}{$\mathrm{CoFe}_{\mathrm{p}}$} & \multirow{3}{*}{$\operatorname{Co} 2 p^{3 / 2}$} & 780 & Octahedral $\mathrm{Co}^{2+}$ & 55 & \multirow{9}{*}{31} \\
\hline & & 781.9 & tetrahedral $\mathrm{Co}^{2+}$ & 45 & \\
\hline & & 785.5 & satellite peak of $\mathrm{Co}^{2+}$ & - & \\
\hline & \multirow{3}{*}{$\mathrm{Fe} 2 \mathrm{p}^{3 / 2}$} & 710.5 & octahedral Fe $\mathrm{Fe}^{3+}$ & 72.5 & \\
\hline & & 713.2 & tetrahedral $\mathrm{Fe}^{3+}$ & 27.5 & \\
\hline & & 716.7 & Satellite peak $\mathrm{Fe}^{3+}$ & - & \\
\hline & \multirow{3}{*}{$\mathrm{O} 1 \mathrm{~s}$} & 529.7 & $\mathrm{CoFe}_{2} \mathrm{O}_{4}$ & 80 & \\
\hline & & 531.5 & $\mathrm{CoFe}_{2} \mathrm{O}_{4}$ & 12 & \\
\hline & & 534.5 & Artifact & 8 & \\
\hline \multirow{9}{*}{$\mathrm{CoFe}_{\mathrm{g}}$} & \multirow{3}{*}{ Co $2 \mathrm{p}^{3 / 2}$} & 779.9 & Octahedral $\mathrm{Co}^{2+}$ & 63 & \multirow{9}{*}{21} \\
\hline & & 781.6 & tetrahedral $\mathrm{Co}^{2+}$ & 37 & \\
\hline & & 784.4 & Octahedral $\mathrm{Co}^{2+}$ & - & \\
\hline & \multirow{3}{*}{$\mathrm{Fe} 2 \mathrm{p}^{3 / 2}$} & 710.9 & octahedral Fe $\mathrm{Fe}^{3+}$ & 68.5 & \\
\hline & & 713.1 & tetrahedral $\mathrm{Fe}^{3+}$ & 31.5 & \\
\hline & & 717.1 & Satellite peak $\mathrm{Fe}^{3+}$ & - & \\
\hline & \multirow{3}{*}{$\mathrm{O} 1 \mathrm{~s}$} & 529.9 & $\mathrm{CoFe}_{2} \mathrm{O}_{4}$ & 78 & \\
\hline & & 531.5 & $\mathrm{CoFe}_{2} \mathrm{O}_{4}$ & 13 & \\
\hline & & 534.5 & Artifact & 9 & \\
\hline
\end{tabular}

To investigate the cation valence states and their distribution in the $\mathrm{CoFe}_{2} \mathrm{O}_{4}$ spinel, the high-resolution XPS spectra of Fe 2p, Co 2p, and O1s peaks of the $\mathrm{CoFe}_{2} \mathrm{O}_{4}$ specimen were studied and given for $\mathrm{CoFe}_{\mathrm{g}}$ in Figure 5. The integrated intensities of the fitted peaks of $\mathrm{Co}^{2+}$ and $\mathrm{Fe}^{3+}$ ions were used to determine their distributions in both octahedral and tetrahedral positions. The table also shows an increase in the concentration of $\mathrm{Fe}^{3+}$ cations on octahedral sites with the increase in the particle size of the sample, which agrees well with XRD data. In conclusion, it can be said that the selection of the preparation route is effective in controlling the cation distribution within the spinel lattice. The presence of high intense satellite structure on the high binding energy side of the Co $2 \mathrm{p}^{3 / 2}$ and $\mathrm{Fe} 2 \mathrm{p}^{3 / 2}$ might be attributed to the band structure related to octahedral Co $2 \mathrm{p}$ in the oxide lattice.

\subsection{Magnetic study.}

To investigate the effect of the synthetic method on the magnetic properties, the VSM test was done at room temperature in an applied field of $10 \mathrm{kOe}$. The results are represented in 
Figure 6, which shows hysteresis loops referring to the ferromagnetic nature of all samples. The $M(H)$ curves also show a linear part at higher magnetic fields, signifying a meaningful paramagnetic contribution to the magnetization. The saturation magnetizations $\left(M_{s}\right)$ are evaluated by extrapolating the plots of $M$ vs. $1 / H$ employing data at high magnetic fields [14]. The magnetic parameters are extracted from $M-H$ plots Figure 6 and listed in Table 3. The coercivity $\left(H_{c}\right)$, remanent magnetization $\left(M_{\mathrm{r}}\right)$ are extracted from $M-H$ plots (Figure 6$)$ and listed with the saturation magnetizations $\left(M_{s}\right)$ and the squareness values of the hysteresis loops for all specimens in Table 3 . The small values of the coercivity $\left(H_{c}\right)$ of $\mathrm{CoFe}_{2} \mathrm{O}_{4}$ nanoparticles denote that the studied samples lie near the super-paramagnetic limit.
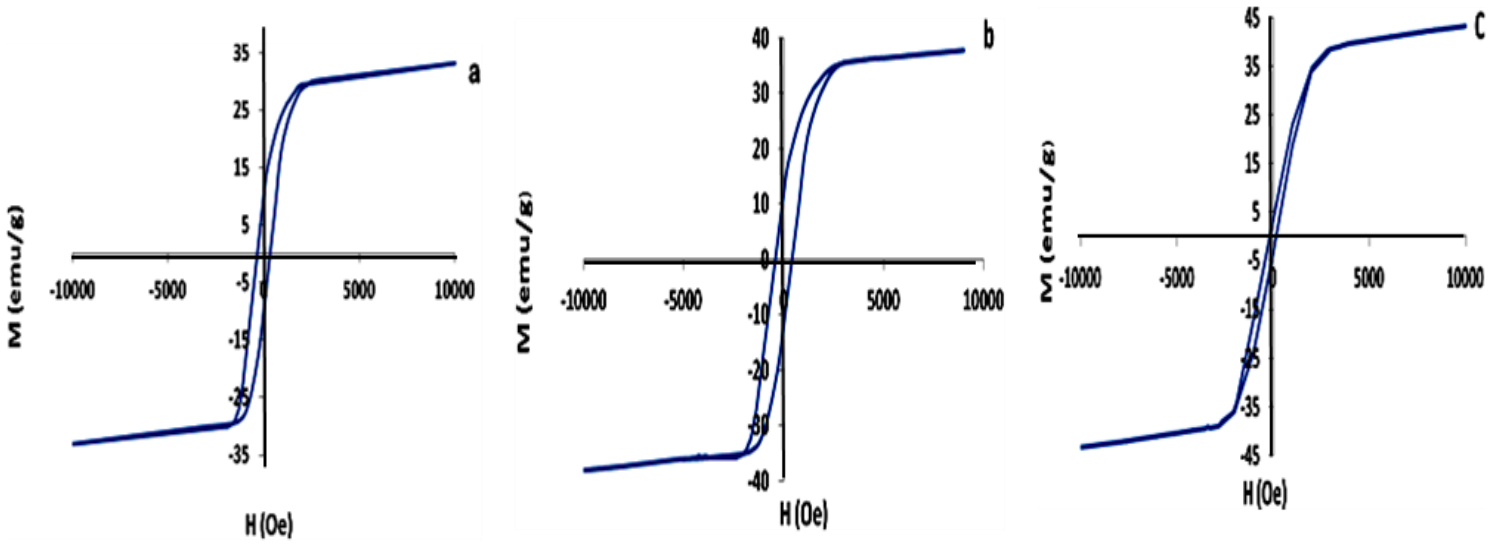

Figure 6. Magnetic hysteresis of investigated samples: (a) $\mathrm{CoFe}_{\mathrm{g}}$; (b) $\mathrm{CoFe}_{\mathrm{p}}$; (c) $\mathrm{CoFe}_{\mathrm{s}}$.

For the ideal inverse spinel crystal structure of $\mathrm{CoFe}_{2} \mathrm{O}_{4}$, with all the $\mathrm{Co}^{2+}$ ions located at the octahedral site, the magnetization per formula unit can be theoretically evaluated using Neel's two sublattice model by considering the difference of total magnetic moments in

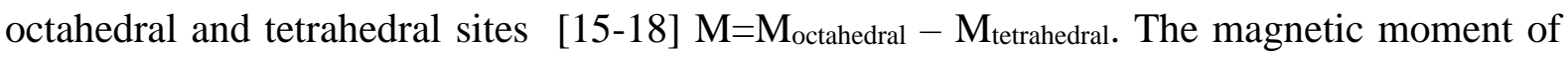
$\mathrm{Fe}^{3+}$ and $\mathrm{Co}^{2+}$ cations are 5.0 and $3.8 \mu \mathrm{B}$, respectively, the theoretical magnetic moment of $\mathrm{CoFe}_{2} \mathrm{O}_{4}$ is $3.8 \mu \mathrm{B}$ per formula unit. Based on the cation distribution obtained from XPS, the magnetization per formula unit was also calculated and listed in Table 3, which shows that the magnetic moments change with the preparation methods. The magnetic moment values of the investigated samples can also be determined experimentally by the following equation in Bohr magneton:

$$
\mu_{\mathrm{B}}=\mathrm{Mol} . \mathrm{wt} \times \mathrm{Ms} / 5585
$$

However, the evaluated data from XPS and VSM are not equal, which can be associated with the finite size of nanoparticles conducting to the noncollinearity of magnetic moments on the surface of the nanoparticles. The disordered moments are developed due to the broken exchange bonds at the outer layer. On the other hand, the competition antiferromagnetic interactions precede a noncollinear arrangement of magnetic moments within interstitial sublattices induced by the non-equilibrium cation distribution among tetrahedral and octahedral sites $[15,17,18]$. Shifting of larger $\mathrm{Co}^{2+}(0.78 \AA)$ to substitute the smaller $\mathrm{Fe}^{3+}(0.645$ $\AA$ ) cations in octahedral sites produce strains on the surface due to the smaller space between the octahedral site cations comparable to the tetrahedral site cations in nanoparticles. The strains obtained can break the surface exchange bonds, which cause the canted spin structure. This type of tetrahedral-octahedral interaction points to lower magnetization values in the ferrite nanoparticles than the bulk $\mathrm{CoFe}_{2} \mathrm{O}_{4}$ [17]. The low $M_{s}$-value of the investigate ferrite 
samples compared with that of the bulk one $(80.9 \mathrm{emu} / \mathrm{g})$ [3] can also be explained based on the core-shell model, which clarifies that the finite-size effects of the nanoparticles manage to canting or non-collinearity of spins on their surface, in that way reducing magnetization [16].

To sum up, it can be said that the change in saturation magnetization with the variation in the preparation methods is possibly due to the rearrangement of the cation distribution, i.e., the exchange of $\mathrm{Co}^{2+}$ and $\mathrm{Fe}^{3+}$ ions from octahedral and tetrahedral sites and vice versa. The low values of $\mathrm{M}_{\mathrm{s}}$ for the investigated samples could be credited to surface distortion, which destabilizes the collinear spin arrangement and producing various canted spin structures at the surface. This effect is especially noticeable for ultrafine particles owing to their large surfaceto-volume ratio. The reduction in coercivity with increasing particle size could be accredited to the combination of surface anisotropy and thermal energies [19].

The values of the squareness ratio $\left(\mathrm{M}_{\mathrm{r}} / \mathrm{M}_{\mathrm{s}}\right)$ of investigated samples, shown in Table 3, are below 0.5 refers to that these samples are multidomain, and the particles interact by magnetostatic interaction [20].

The magnetic anisotropy $\left(\mathrm{K}^{\prime}\right)$ has also been calculated using the following relation [21],

$$
\mathrm{H}_{\mathrm{c}}=0.98 \mathrm{~K}^{\prime} / \mathrm{M}_{\mathrm{s}}
$$

and the results obtained showed high values of 16711, 13571, and $6181 \mathrm{emu}^{-\mathrm{Oeg}^{-1}}$ for $\mathrm{CoFe}_{\mathrm{p}}$, $\mathrm{CoFe}_{\mathrm{g}}$, and $\mathrm{CoFe}_{s}$, respectively. The increase in $\mathrm{K}$ value is going parallel with increasing the presence of $\mathrm{Co}^{2+}$ ions in the octahedral sites, as shown in XPS results (Table 2).

The effect of the preparation method on the magnetic parameters of our $\mathrm{CoFe}_{2} \mathrm{O}_{4}$ nanoparticles is compared with other methods present in the literature and listed in Table 4.

Table 4. Effect of the preparation methods on magnetic parameters of $\mathrm{CoFe}_{2} \mathrm{O}_{4}$ nanoparticles.

\begin{tabular}{l|c|c|c|c|c}
\hline \multicolumn{1}{c|}{$\begin{array}{c}\text { Preparation } \\
\text { method }\end{array}$} & Particle Size $(\mathbf{n m})$ & $\mathbf{M}_{\mathbf{s}}(\mathbf{e m u} / \mathbf{g})$ & $\mathbf{M}_{\mathbf{r}}(\mathbf{e m u} / \mathbf{g})$ & $\mathbf{H}_{\mathbf{c}}(\mathbf{O e})$ & Reference \\
\hline Green & 21 & 38.0 & 10.1 & 370 & Present work \\
Co-precipitation & 31 & 43.1 & 12.5 & 360 & Present work \\
ceramic & 36 & 46.6 & 3.69 & 130 & Present work \\
combustion & 33 & 31.6 & 9.6 & 870 & {$[22]$} \\
Co-precipitation & 32 & 35.6 & 13 & 614 & {$[23]$} \\
Sol-gel & 5.5 & 2.4 & 8.9 & 434 & {$[24]$} \\
Co-precipitation & 42 & 10.4 & 10 & 500 & {$[25]$} \\
Co-precipitation & 21 & 30 & 10 & 100 & {$[26]$} \\
Sol-gel & 18 & 60 & 23 & 150 & {$[27]$} \\
hydrothermal & 120 & 1.58 & 0.612 & 1357 & {$[29]$} \\
Microemulsion & 28 & & & & \\
\hline
\end{tabular}

\subsection{Surface properties.}

The surface properties of the spinels investigated were studied using the BET technique. The isothermal $\mathrm{N}_{2}$ adsorption-desorption plots of these samples Figure 7 can be classified as type IV for $\mathrm{CoFe}_{\mathrm{p}}$ and type $\mathrm{V}$ for $\mathrm{CoFe}_{\mathrm{g}}$ and $\mathrm{CoFe}_{\mathrm{s}}$ according to IUPAC, which is characteristic of the mesoporous material in which the adsorption proceeds via multilayer adsorption followed by capillary condensation. The hysteresis loops show the type H3 (aggregates of platelike particles forming slit-shaped pores) for all samples. The studied samples' textural properties, including BET-surface area, average pore diameter, pore-volume, and pore size distribution calculated from $\mathrm{BJH}$ method, are derived from $\mathrm{N}_{2}$ nitrogen adsorption/desorption isotherms and listed in Table 5. The data obtained refer to that the surface properties depend largely on the method of preparation, and $\mathrm{CoFe}_{\mathrm{g}}$ exhibits the highest surface area. 


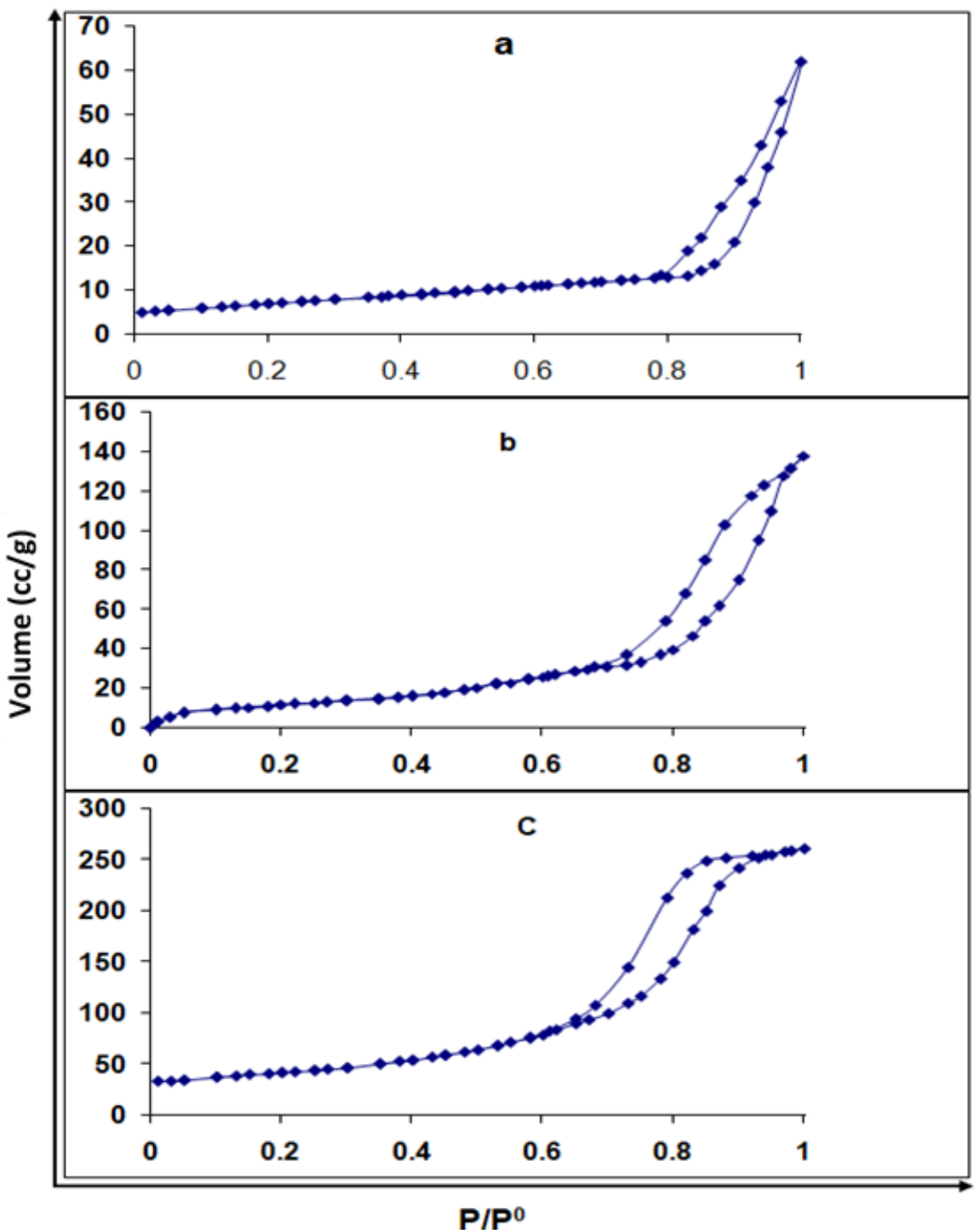

Figure 7. Nitrogen adsorption-desorption isotherms of investigated samples, (a) $\mathrm{CoFe}_{\mathrm{g}} ;(\mathbf{b}) \mathrm{CoFe}_{\mathrm{p}}$; (c) $\mathrm{CoFe}_{\mathrm{s}}$.

Table 5. Textural surface data obtained from BET measurements for $\mathrm{CoFe}_{2} \mathrm{O}_{4}$ samples.

\begin{tabular}{c|c|c|c|c|c|c}
\hline Samples & $\begin{array}{c}\text { Particle size dxRD } \\
(\mathbf{n m})\end{array}$ & $\mathbf{V}_{\mathbf{s t}}(\mathbf{m l} / \mathbf{g})$ & $\mathbf{V}_{\mathbf{p}}(\mathbf{m l} / \mathbf{g})$ & $\mathbf{V}_{\mathbf{m}}(\mathbf{m l} / \mathbf{g})$ & $\begin{array}{c}\text { S } \\
\left(\mathbf{m}^{2} / \mathbf{g m}\right)\end{array}$ & $\mathbf{r}(\AA)$ \\
\hline $\mathbf{C o F e}_{\mathbf{s}}$ & 36 & 62 & 0.09 & 6 & 25 & 98 \\
\hline $\mathbf{C o F e}_{\mathbf{p}}$ & 31 & 138 & 0.21 & 10 & 45 & 89 \\
\hline $\mathbf{C o F e}_{\mathbf{g}}$ & 21 & 261 & 0.40 & 32 & 99 & 73 \\
\hline
\end{tabular}

\subsection{Optical properties.}

The prepared $\mathrm{CoFe}_{2} \mathrm{O}_{4}$ nanoparticles show still high magnetization, that photocatalyst appropriate for magnetically separable by a magnetic field and separation of photocatalyst from solution. Thus, the photocatalytic activity of the investigated samples has been studied. The optical absorption property related to the electronic structure characteristic is documented as the main factor in deciding the photocatalytic activity [30]. The diffuse reflectance spectra of our ferrites were recorded and converted to the Kubelka-Munk function, K-M, Figure 8, using the following equation:

$$
\mathrm{K}-\mathrm{M}=(1-\mathrm{R})^{2} / 2 \mathrm{R}
$$

Where $R$ is absolute reflectance, the results obtained are listed in Figure 8A. The spectra show that all synthesized $\mathrm{CoFe}_{2} \mathrm{O}_{4}$ samples exhibited photo-absorption in the visible light 
region, which implies the probability of high photocatalytic efficiency of these materials under visible light. The absorption behavior in the visible region is originated from the electronic charge transformation of $\mathrm{Co}^{2+}$ and $\mathrm{Fe}^{3+}$ to their conduction level in the conduction band $[7,31$, 32]. The $\mathrm{CoFe}_{2} \mathrm{O}_{4}$ stoichiometry is organized in an incompletely inverse structure [27], with the $\mathrm{Co}^{2+}$ ion at both tetrahedral and octahedral sites, as shown in our results (XRD, XPS, and magnetic data).
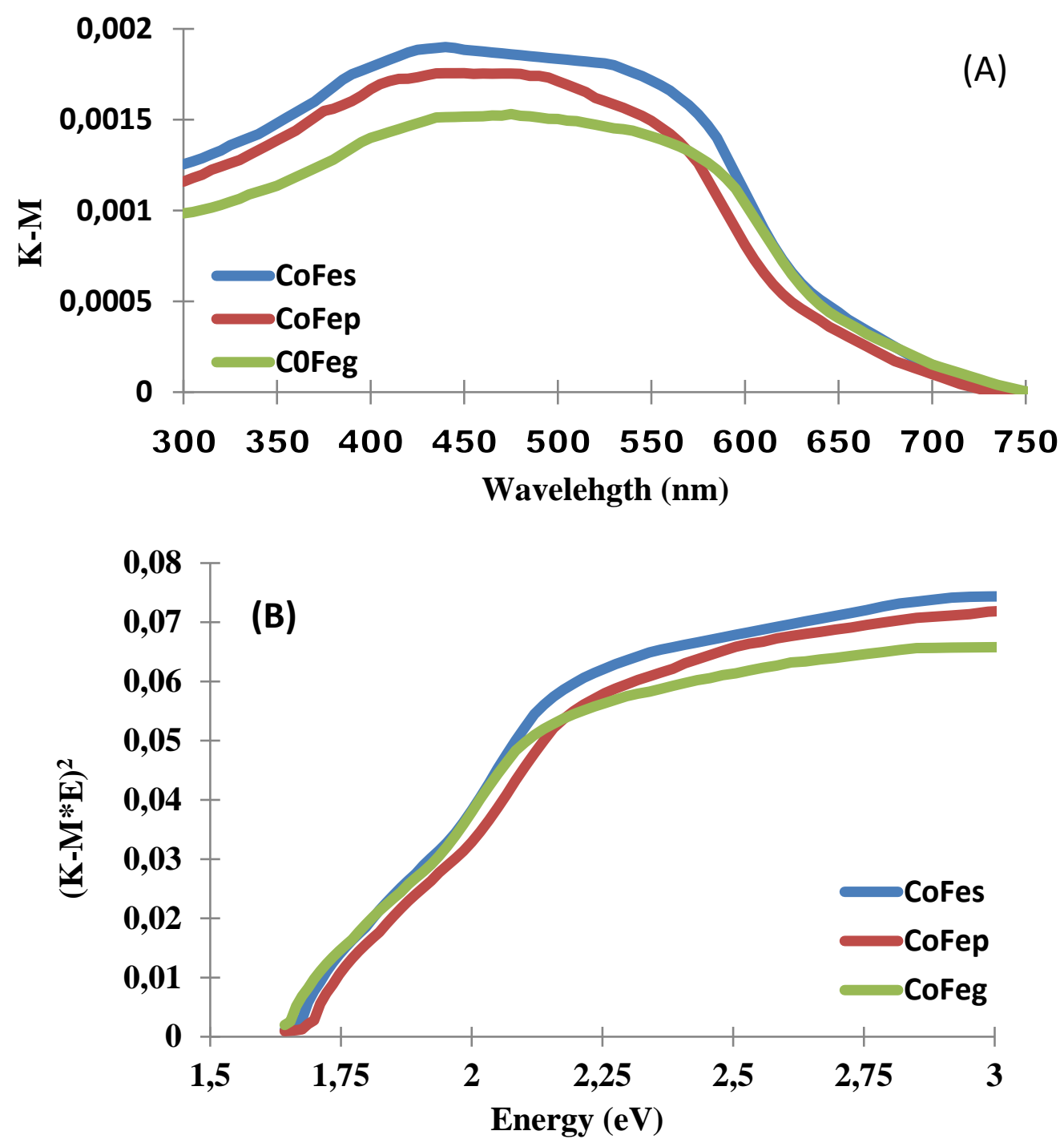

Figure 8. (A) UV-vis spectra presented as the Kubelka-Munk function for $\mathrm{CoFe}_{2} \mathrm{O}_{4}$ nanoparticles; (B) Tauc's plots for $\mathrm{CoFe}_{2} \mathrm{O}_{4}$ nanoparticles.

Broad $\mathrm{Co}-\mathrm{O}$ and $\mathrm{Fe}-\mathrm{O}$ charge transfers, together with $\mathrm{d}-\mathrm{d}$ electron moves of $\mathrm{Co}^{2+}$ and $\mathrm{Fe}^{3+}$ in numerous coordination, guarantee the full absorption of the visible spectrum. The bandgap energies of the investigated ferrites were estimated according to Tauc's [33] by plotting $(\mathrm{KM} . \mathrm{h} v) 1 / \mathrm{n}$ versus $\mathrm{h} v$, where $\mathrm{h}$ is a Planck's constant, $\mathrm{n}$ is the light frequency, and $\mathrm{n}$ is a constant relating to a mode of transition ( $n=1 / 2$ for allowed direct transition and $\mathrm{n}=2$ for indirect transition). Tauc's plots, shown in Figure 8-b, for every one of the specimens, demonstrated that the band-to-band direct transitions are more inclined to happen than the indirect transitions. The optical energy gaps, $\mathrm{E}_{\mathrm{g}}$, obtained from the intercept of the plot with the $\mathrm{X}$-axis are recorded in Table 6, from which it can be seen that $\mathrm{E}_{\mathrm{g}}$ value decreases with increasing the particle size and showed the smallest value for $\mathrm{CoFe}_{\mathrm{g}}$ sample. 
Table 6. Optical and surface acidity data of $\mathrm{CoFe}_{2} \mathrm{O}_{4}$ samples Table 6. Optical and surface acidity data of $\mathrm{CoFe}_{2} \mathrm{O}_{4}$ samples.

\begin{tabular}{c|c|c|c|c|c|c|c}
\hline Samples & $\begin{array}{c}\text { Particle } \\
\text { size (nm) }\end{array}$ & $\begin{array}{c}\lambda_{\max } \\
(\mathbf{n m})\end{array}$ & $\begin{array}{c}\mathbf{E}_{\mathbf{g}} \\
(\mathbf{e V})\end{array}$ & $\begin{array}{c}\text { Surface } \\
\text { Acidity sites } \\
\text { Weak } \\
(\mathbf{m m o l} / \mathbf{g})\end{array}$ & $\begin{array}{c}\text { Surface Acidity } \\
\text { sites medium } \\
(\mathbf{m m o l} / \mathbf{g})\end{array}$ & $\begin{array}{c}\text { Surface } \\
\text { Acidity sites } \\
\text { Strong } \\
(\mathbf{m m o l} / \mathbf{g})\end{array}$ & $\begin{array}{c}\text { Surface } \\
\text { Acidity } \\
\text { Total } \\
\text { sites } \\
(\mathbf{m m o l} / \mathbf{g})\end{array}$ \\
\hline $\mathrm{Bulk}$ & --- & 790 & 2.0 & - & - & - & - \\
\hline $\mathrm{CoFe}_{\mathrm{s}}$ & 36 & 590 & 1.39 & 7.5 & 5.5 & 3.0 & 16.0 \\
\hline $\mathrm{CoFe}_{\mathrm{p}}$ & 31 & 610 & 1.38 & 6.0 & 4.1 & 2.1 & 13.2 \\
\hline $\mathrm{CoFe}_{\mathrm{g}}$ & 21 & 620 & 1.37 & 11.0 & 6.1 & 4.0 & 21.1 \\
\hline
\end{tabular}

\subsubsection{Raman spectroscopy.}

Raman spectra were used to acquire a vision of the vibrational energy states within the spinel ferrite and review the structural characteristics and compositional regularity throughout the samples [34]. The spinel ferrite exhibit five active Raman vibration modes [35,36]. The Raman spectra of our samples showed only three bands, due to peak overlapping, at 284-297 $\mathrm{cm}^{-1}, 460-470 \mathrm{~cm}^{-1}$, and 640-650 $\mathrm{cm}^{-1}$, as shown in Figure 9, which was assigned as $\mathrm{E}_{\mathrm{g}}, 3 \mathrm{~T}_{2 \mathrm{~g}}$ and $A_{1 g}(1)$, respectively [37]. The $A_{1 g}(1)$ band is related to symmetric stretching vibration mode at the tetrahedral (A) site. While $\mathrm{A}_{1 \mathrm{~g}}(1)$ band might be related to the vibration of Co-O bonds at the tetrahedral (A) site. The results obtained in Figure 9; show that the frequency of Raman modes of the investigated spinels is slightly changed with the preparation method. This could be attributed to the variation in the cation distribution in the spinel lattice, as mentioned above.

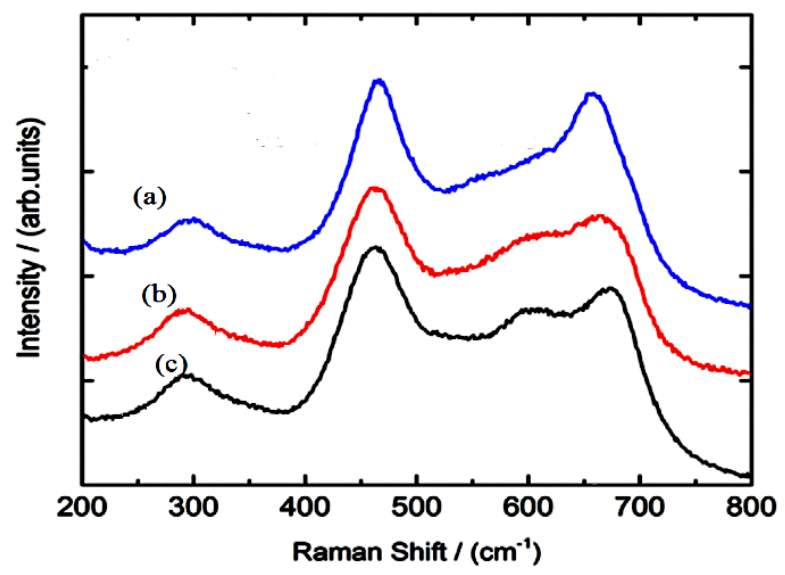

Figure 9. Raman spectra of investigated samples: (a) $\mathrm{CoFe}_{\mathrm{g}}$; (b) $\mathrm{CoFe}_{\mathrm{p}}$; (c) $\mathrm{CoFe}_{\mathrm{s}}$.

\subsubsection{Photoluminescence study.}

Photoluminescence (PL) spectroscopy is an outstanding procedure to get valuable information concerning energy and the dynamics of charge carriers yielded during the exposure of light. The photoluminescence of the ferrite nanoparticles was studied using a $225 \mathrm{~nm}$ excitation wavelength source, and the results obtained are presented in Figure 10. The spectra of all samples show broad visible emission peaks at $434-442 \mathrm{~nm}$, which are attributed to the charge transport between $\mathrm{Co}^{2+}$ at tetrahedral sites and $\mathrm{Fe}^{3+}$ at octahedral sites that are surrounded by $\mathrm{O}^{2-}$ ions [38]. The variation in the position and the intensity of luminescence can be explained on the basis that the PL-spectra are sensitive to the character of nanoparticles surface due to the existence of gap surface disorders developing from surface nonstoichiometry and unsaturated bonds. The defects produced in the nanomaterial lattice during preparation are the base of luminescent properties [39]. The emission intensity of $\mathrm{CoFe}_{\mathrm{g}}$ is 
lower than that of the rest samples. This indicates that this sample acted as traps for the photoinduced charge carriers. These outcomes confirm the previously mentioned results on the influence of the preparation methods on the surface and optical properties.

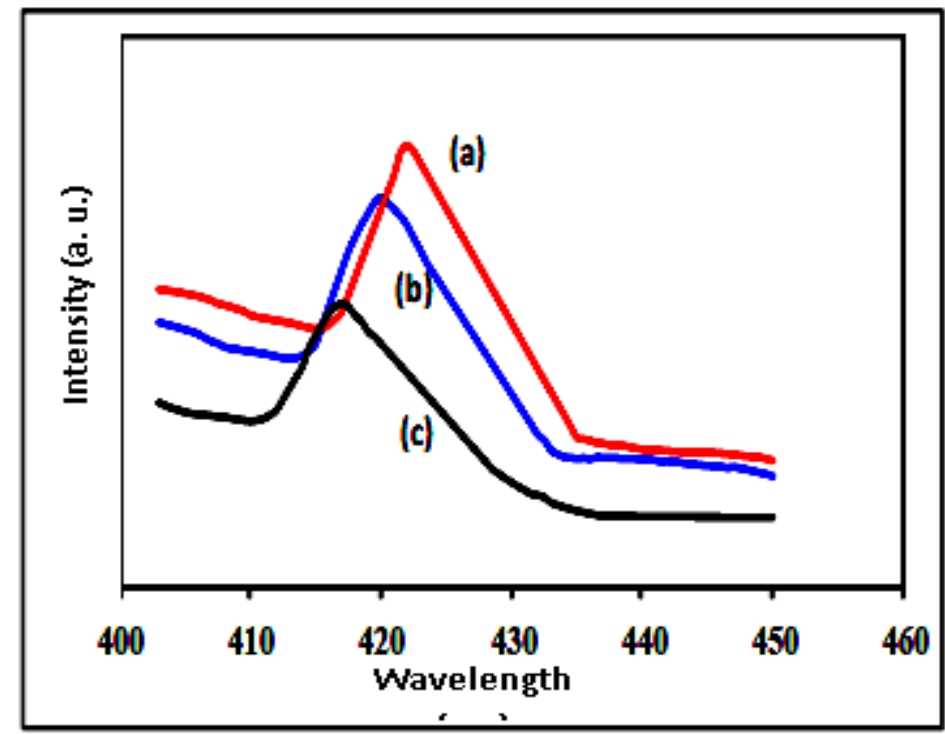

Figure 10. Photolumiscence spectra of investigated samples: (a) $\mathrm{CoFe}_{\mathrm{p}} ;$ (b) $\mathrm{CoFe}_{\mathrm{s}} ;(\mathbf{c}) \mathrm{CoFe}_{\mathrm{g}}$.

\subsubsection{Surface acidity.}

Temperature-programmed desorption of ammonia (TPD- $\mathrm{NH}_{3}$ ) is an appropriate procedure for measuring the quantity and the spreading of the acid sites on the surface of our samples. The acid site distribution results for the studied samples are summarized in Table 6. The ammonia desorbed at $100{ }^{\circ} \mathrm{C}$ contains some physisorbed ammonia as well as overstating the proportion of weak acid sites. Whereas, the ammonia desorbed at $220-370{ }^{\circ} \mathrm{C}$ and that at 450-600 ${ }^{\circ} \mathrm{C}$ are attributed to medium and strong acid sites, respectively [40]. The results obtained show that the acidity varies with preparation methods. For all samples, the strength of acidic sites follows the order: Weak acid sites $>$ medium sites $>$ strong acid sites. CoFe exhibits the highest total acidity than that of other samples.

\subsection{Photocatalytic activity of $\mathrm{CoFe}_{2} \mathrm{O}_{4}$ samples.}

According to the above-mentioned optical properties, we studied the photocatalytic activity of the investigated $\mathrm{CoFe}_{2} \mathrm{O}_{4}$ nanoparticles under visible light irradiation using the degradation of Basic Red 18 (BR 18) aqueous solution as a basic dye model. Before the irradiation process, the suspended solution of the dye and catalyst was stored in the dark for 45 min. to assurance adsorption/desorption equilibrium. The photocatalytic degradation results are illustrated in Figure 11. From which it can be seen that the degradation of the dye is very slow in the absence of the catalyst and the CoFeg sample showed the highest photocatalytic efficiency due to the high optical absorptions in vis. The light region with lower bandgap energy and a larger surface area. Therefore, this sample was selected to test the impact of catalyst dosage, dye concentration, and $\mathrm{pH}$ of the solution on the dye degradation rate. The results obtained given in Fig. 11 show that the rate of dye degradation has the highest rate at 3 $\mathrm{mg} / \mathrm{L}$ catalyst dosage and decreases with increasing dye concentration in the range of $10-100$ ppm and has the highest $\mathrm{pH}=7$ of the solution. 
Given literature reports, the kinetic of photocatalytic reaction can be calculated according to:

$$
-\ln (\mathrm{C} / \mathrm{Co})=\text { kobs } \mathrm{t}
$$

where $\mathrm{Co}$ and $\mathrm{C}$ are the concentrations of dye at zero time and time $\mathrm{t}$, respectively, and $\mathrm{k}_{\text {obs }}$ are the pseudo-first-order rate constant. The rate constant, kobs, evaluated from the slope of the straight line of plotting $-\ln (C / C 0)$ vs. reaction time, Figure 11-b showed a value of $0.1 \mathrm{~min}^{-1}$.
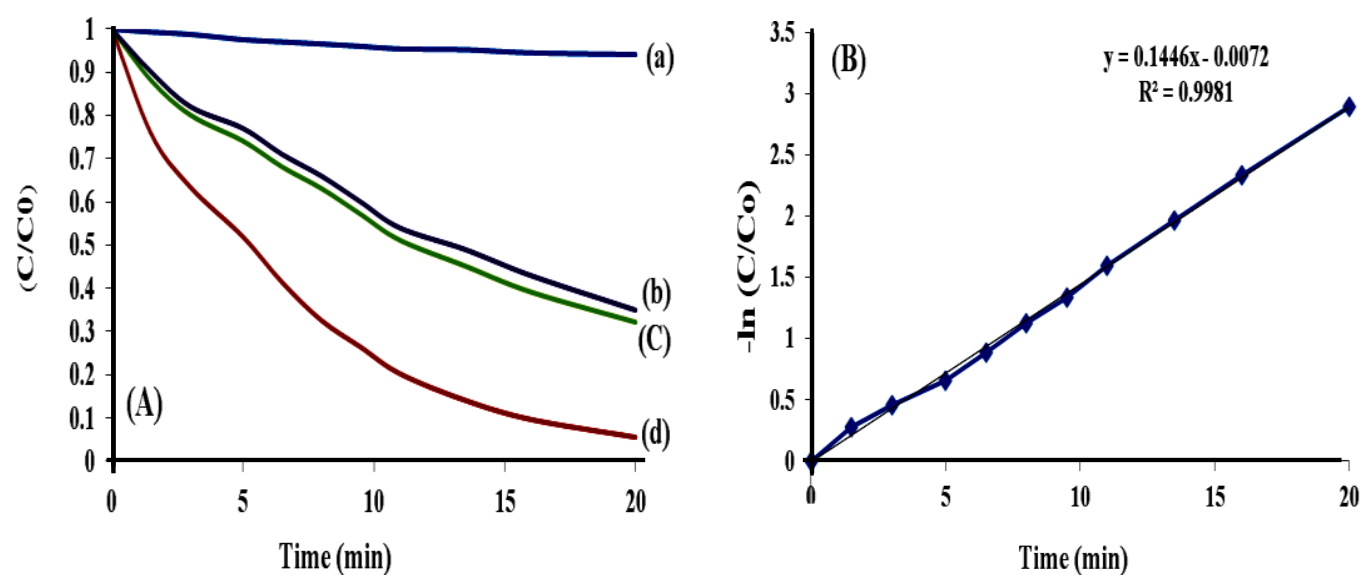

Figure 11. (A) Photocatalytic degradation rate for $10 \mathrm{ppm}$ Basic Red 18 over investigated $\mathrm{CoFe}_{2} \mathrm{O}_{4} \mathrm{samples}_{\text {at }}$ $\mathrm{pH}=7$ : dye solution without catalyst, and in the presence of $3 \mathrm{mg} / \mathrm{L}$ catalysts of (b) $\mathrm{CoFe}_{\mathrm{s}}$; (c) $\mathrm{CoFe}_{\mathrm{p}}$ and (d)

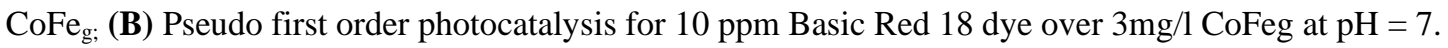

\subsubsection{Mechanism of photocatalysis.}

The major oxidative species in the photocatalytic progression are positive holes $\left(\mathrm{h}^{+} / \mathrm{VB}\right)$ and the $\mathrm{OH}^{-}$hydroxyl radical formed during the irradiation process. In the present work, the trapping experiments were used to determine which one of these species is active for organic degradation.

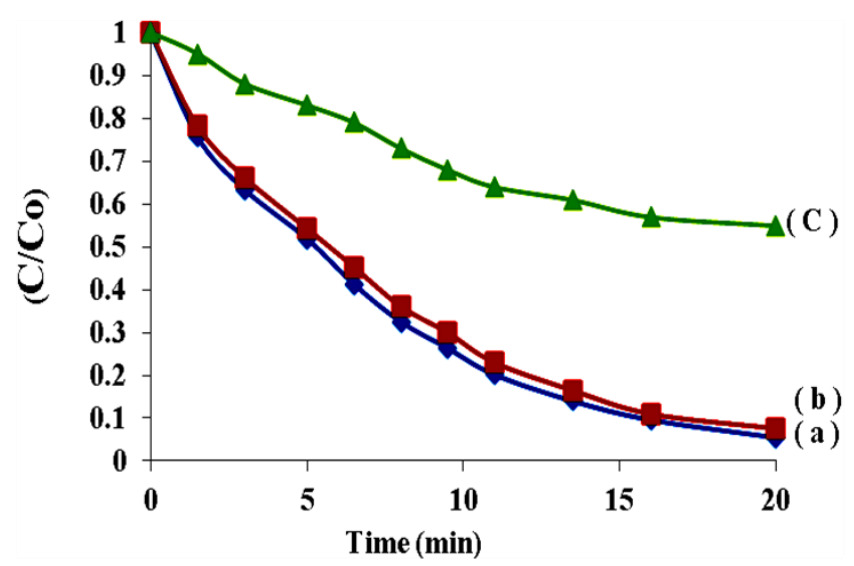

Figure 12. Effect of additives on the photocatalytic degradation rate of 10 ppm Basic Red 18 over 3 $\mathrm{mg} / \mathrm{L} \mathrm{FeCog}$ at $\mathrm{pH}=7$ : (a) Without additive (b) Isopropyl alcohol (c) EDTA.

EDTA-2Na and isopropyl alcohol were used as an $\mathrm{H}^{+}$, and isopropyl alcohol as an $\mathrm{OH}^{\cdot}$ scavenger, respectively [32]. The results showed that the additive of isopropyl alcohol slightly changed the dye degradation, indicating that $\mathrm{OH}$ radicals were minor factors in the photocatalytic degradation process, whereas the addition of $\mathrm{h}^{+}$capture (EDTA-2Na) caused a great decrease in the degradation efficiency, as shown in Figure 12. This foundation distinctly denoted that positive holes are the major active species of dye dissociation. 


\section{Conclusions}

Nanosized cobalt ferrite $\left(\mathrm{CoFe}_{2} \mathrm{O}_{4}\right)$ particles are synthesized through three different methods (sol-gel, solid-state blending, and co-precipitation). The proposed preparations are inexpensive and thus appropriate for the large-scale production of such type nanoparticles. XRD approves the formation of a spinel phase in all preparation methods. The FT-IR spectra displayed two characteristic metal-oxygen vibrational bands for the spinel structure. The results reveal that the synthetic route affected each particle size, morphological structure, surface textures, surface acidic properties, cation distribution, optical and magnetic properties. Both $\mathrm{Fe}^{3+}$ and $\mathrm{Co}^{2+}$ are distributed in octahedral and tetrahedral sites in a ratio depending on the preparation method. The variation in this ratio controlled the studied properties. The results showed that the prepared ferrite exhibits either ferromagnetic or super-paramagnetic behavior with magnetic parameters of particular importance for allowing the magnetic recovery and reuse of the catalyst and the possibility to be used in recording media. Ammonia TPD analyses showed that weak acid sites prevail medium-strength sites, whereas the number of strong acid sites is the least. The obtained ferrite is utilized as photocatalytic for degradation Basic Red 18 (BR 18) dye under visible light irradiation with the highest degradation rate for the sample prepared by the gel method. The prepared ferrite photocatalysts can potentially be used for cleaning polluted water with the help of magnetic separation.

\section{Funding}

This research received no external funding.

\section{Acknowledgments}

The authors declare no acknowledgments.

\section{Conflicts of Interest}

The authors declare no conflict of interest.

\section{References}

1. Gratiet, A. L.; Amora, M. D.; Duocastella, M.; Marongiu, R.; Bendand, A.; Giordani, S.; Bianchini, P.; Diaspro, A. Zebrafish structural development in Mueller-matrix scanning microscopy, J. Scien. Repor. 2019, 9, 19974-19984.

2. Prabhakaran, T.; Mangalaraja, R.V.; Denardin, J.C.; Jimenez, J.A. The effect of calcination temperature on the structural and magnetic properties of co-precipitated $\mathrm{CoFe}_{2} \mathrm{O}_{4}$ nanoparticles. J. Alloys Compd. 2017, 716, $171-183$.

3. Safi, R.; Ghasemi, A.; Shoja-Razavi, R. Factors controlling magnetic properties of $\mathrm{CoFe}_{2} \mathrm{O}_{4}$ nanoparticles synthesized by chemical co-precipitation: Modeling and optimization using response surface methodology. Ceram. Int. 2016, 42 ,15818-15825.

4. Vilém, B.; David, S.; Štepán, H. ; Švecová, M.; Pavel, U.; Ondrej, J. Synthesis and Properties of Nanosized Stoichiometric Cobalt Ferrite Spinel. Materials 2018, 11, 1241.

5. Jalalian, M.; Mirkazemi, S.M. ; Alamolhoda, S. Phase constituents and magnetic properties of the $\mathrm{CoFe}_{2} \mathrm{O}_{4}$ nanoparticles prepared by polyvinylpyrrolidone (PVP)-assisted hydrothermal route. Appl. Phys. 2016, A 122, 835 .

6. Liu, M.; Lu, M.; Wang, L.; Xu, S.C. ; Zhao, J.L.; Li, H.B. Mossbauer study on the magnetic properties and cation distribution of $\mathrm{CoFe}_{2} \mathrm{O}_{4}$ nanoparticles synthesized by hydrothermal method. J. Mater. Sci. 2016, 51, 5487-5492. 
7. Mishra, S.; Sahoo, S.S.; Debnath, A.K.; Muthe, K.P.; Dasb, N.; P. Cobalt ferrite nanoparticles prepared by microwave hydrothermal synthesis and adsorption efficiency for organic dyes: Isotherms, thermodynamics and kinetic studies, J. Advan. Powde. Techno. 2020, 31, 11, 4552-4562.

8. Ikram, S.; Arshad, M. I.; Mahmood, K.; Alia, A.; Amin, N. Structural, magnetic and dielectric study of La3+ substituted $\mathrm{Cu} 0.8 \mathrm{Cd} 0.2 \mathrm{Fe}_{2} \mathrm{O}_{4}$ ferrite nanoparticles synthesized by the co-precipitation method. $J$. Alloy.Compo. 2018, 15, 1019-1025.

9. Yadava, R. S.; Kuřitka, I.; Vilcakova, J.; Havlica, J.; Kalina, L.; Urbánek, P.; Machovsky, M.; Skoda, D.; Masař, M.; Holek, M.; Sonochemical synthesis of $\mathrm{Gd}^{3+}$ doped $\mathrm{CoFe}_{2} \mathrm{O}_{4}$ spinel ferrite nanoparticles and its physical properties. J. Ultraso. Sonochem. 2018, 40, 773-783.

10. Samoila, P.; Cojocaru, C.; Sacarescu, L.; Dorneanu, P.P.; Domocos, A.-A.; Aurelian Rotaruca, Remarkable catalytic properties of rare-earth doped nickel ferrites synthesized by sol-gel auto-combustion with maleic acid as fuel for CWPO of dyes. J. Appl. Catal. 2017, B 202 , 21-32.

11. Babu, K.R.; Rao, K.R.; Babu, B. R. $\mathrm{Cu}^{2+}$-modified physical properties of Cobalt-Nickel ferrite, J. Magn. Magn. Mater. 2017, 434, 118-125.

12. Torkian, S.; Ghasemi, A.; Razavi, R. S. Cation distribution and magnetic analysis of wideband microwave absorptive $\mathrm{Co}_{\mathrm{X}} \mathrm{Ni}_{1-\mathrm{x}} \mathrm{Fe}_{2} \mathrm{O}_{4}$ ferrites. Ceram. Int. 2017, 43, 6987-6995.

13. Alves, T. M. L.; Amorim, B. F.; Torres, M.A.M.; Bezerra, C.G.; Medeiros, S.N.; Gastelois, P. L.; Outon, L. E. F.; Macedo, W.A.A. Wasp-waisted behavior in magnetic hysteresis curves of $\mathrm{CoFe}_{2} \mathrm{O}_{4}$ nanopowder at a low temperature: experimental evidence and theoretical approach. $R S C A d v . \mathbf{2 0 1 7}, 7,22187$.

14. Annie, V.P.; Immaculate, N.M.G.; Mahalakshmi, K.; Ansel, M.L.; Jerome, D.S. Study on Cobalt Ferrite Nanoparticles Synthesized by Co-Precipitation Technique for Photo-Fenton Application. Mech. Mater. Sci. Eng. 2017, 9, 110-115.

15. Baldini, A.; Petrecca, M.; Sangregorio, C.; Tamburini, U.A. Magnetic properties of bulk nanocrystalline cobalt ferrite obtained by high-pressure field assisted sintering. J. Phys. D: Appl. Phys. 2021, 54, 194006.

16. Bhagwat, V.R.; Khedkar, M.V.; Kulkarni, G.; Kharat, P.B.; Jadhav, K.M. Dextrose assisted sol-gel auto combustion synthesis and magnetic characterizations of cobalt ferrite nanoparticles. J. AIP Confere. Proceed. 2020, 2265, 030085; https://doi.org/10.1063/5.0017310.

17. Gupta, M.; Das, A.; Mohapatra, S.; Das, D.; Datta, A.; Surfactant based synthesis and magnetic studies of cobalt ferrite. J. Appli. Phys. A 2020, 126, 660.

18. Swatsitang, E.; Phokha, S.; Hunpratub, S.; Usher, B.; Bootchanont, A.; Maensiri, S.; Chindaprasirt, P. Characterization and magnetic properties of cobalt ferrite nanoparticles. J. Alloy. Compo. 2016, 664, 15, 792797.

19. Allaedini, G.; Tasirin, S. M.; Aminayi , P. Magnetic properties of cobalt ferrite synthesized by hydrothermal method. J. Inter. Nano Letter 2015, 5, 183-186.

20. Najeehah, C. Z.; Chaudhary, K. T.; Ali, J. Synthesis and Characterization of Cobalt Ferrite Nanoparticles via Sol-Gel Auto Combustion Method. J. Soli. Stat. Phenom. 2020, 307, 58-63.

21. Ateia1, E.E.; Abdelatif, G.; Soliman, F.S. Optimizing the physical properties of calcium nano ferrites to be suitable in many applications. J Mater. Sci. Mater. Elect. 2017, 28, 5846-5851.

22. Mazrouei, A.; Saidi, A. Microstructure and magnetic properties of cobalt ferrite nano powder prepared by solution combustion synthesis. J. Mater. Chem. Phys. 2018, 209, 152-158.

23. Purnama, B.; Wijayanta, A.T.; Suharyana. Effect of calcination temperature on structural and magnetic properties in cobalt ferrite nano particles. J. King Saud Univ. Sci. 2019, 31, 956-960.

24. Rao, K.S.; Choudaryb, GSVRK.; Rao, K.H.; Sujatha, Ch. Structural and Magnetic properties of Ultrafine $\mathrm{CoFe}_{2} \mathrm{O}_{4}$, J. Nanoparticles. J. Proc. Mater. Sci. 2015, 10, 19-27.

25. Kurian, M. Thankachan, S.; Nair, D.S.; Aswathy. E.K.; Babu, A.; Thomas, A.; Krishna K. T. B. Structural, magnetic, and acidic properties of cobalt ferrite nanoparticles synthesised by wet chemical methods. J. Adv. Ceram. 2015, 4, 199-205.

26. Kovacheva, D.; Ruskov, T.; Krystev, P.; Asenov, S.; Tanev, N.; Mönch, I.; Koseva, R. ; Wolff, U.; Gemming, T.; Markova-Velichkova; Nihtianova, D.; Arndt. Synthesis and characterization of magnetic nano-sized $\mathrm{Fe}_{3} \mathrm{O}_{4}$ and $\mathrm{CoFe}_{2} \mathrm{O}_{4}$. J. Bulg. Chem. Commun. 2012, 44, 90-97.

27. George, T.; Sunny, A. T.; Varghese, T. Magnetic properties of cobalt ferrite nanoparticles synthesized by solgel method. Mater. Sci. and Eng. 2015, 73, 012050. https://doi.org/10.1088/1757-899X/73/1/012050. 
28. Reddy, M. P.; Mohamed, A.M.A.; Zhou, X.B.; Duc, S.; Huang, Q. A facile hydrothermal synthesis, characterization and magnetic properties of mesoporous $\mathrm{CoFe}_{2} \mathrm{O}_{4}$ nanospheres. J Magn. Magnet. Mater. 2015, 388,40-44.

29. Panchal, N.R.; Jotania, R.B. Cobalt ferrite nano particles by microemulsion route. J. Nanotech. Nanosci. 2010, 1, 17-18.

30. Naik, M. M.; Vinuth, M.; Karthik, K..; Suresha, B.; Nagaraju, G.; Sujatha, H. R. Photocatalytic degradation of dyes by cobalt ferrite nanoparticles synthesized by sol-gel method. J. AIP Conferen. Proceed. 2020, 2274, 040004; https://doi.org/10.1063/5.0022559.

31. Andhare, D.D.; Patade, S.R.; Kounsalye, J.S.; Jadhav, K.M. Effect of Zn doping on structural, magnetic and optical properties of cobalt ferrite nanoparticles synthesized via. Co-precipitation method. J. Physica B: Conden. Matte. 2020, 583, 15, 412051.

32. Muthukumaran, T.; Philip, J. Synthesis of water dispersible phosphate capped $\mathrm{CoFe} 2 \mathrm{O} 4$ nanoparticles and its applications in efficient organic dye removal. J. Collo. Surf. A: Physicochem. Engine. Aspec. 2021, 5, 125755.

33. Sharma, I. ; Madara, S. R.; Sharma, P.; Study of Tauc gap, optical density and penetration depth of vacuum evaporated $\mathrm{Pb}_{15} \mathrm{Se}_{85-\mathrm{x}} \mathrm{Ge}_{\mathrm{x}}(\mathrm{x}=0,3,6$ at. \%) thin films supported by chemical bond approach and physical parameters. J. Mate.Today. 2020, 28, 2, 402-407.

34. Schrader, B. Infrared and Raman Spectroscopy: Methods and Applications, VCH: Weinheim, Germany 1995 , $100,807$.

35. Wanga, F.; Mab, Y.; Zhang, H.; Gu, J.; Yin, J.; Jia, X.; Zhang, H.; Wang, Y.; Fu, X.; Yu, R.; Wang, Z.; Han, S.; Wang, G. Rheological properties and sedimentation stability of magnetorheological fluid based on multiwalled carbon nanotubes/cobalt ferrite nanocomposites. J. Molec. Liqu. 2021, 324, 15, 115103.

36. Gil, A. F.; Benavides , O.; Vargas, S. M.; May, L. De. La.C.; Carachure, C. P. Synthesis and Characterization of Cobalt Ferrite $\mathrm{CoxFe}_{3-\mathrm{x}} \mathrm{O}_{4}$ Nanoparticles by Raman Spectroscopy and X-Ray Diffraction. Int .J. Meta. Met. Phys. 2020, 5, 047.

37. Omiddezyani, S.; Gharehkhani, S.; Asli, V. Y.; Khazaee, I.; Ashjaee, M.; Nayebi, R.; Shemirani, F.; Houshfar, E. Experimental investigation on thermo-physical properties and heat transfer characteristics of green synthesized highly stable $\mathrm{CoFe}_{2} \mathrm{O}_{4} / \mathrm{rGO}$ nanofluid. J. Collo. Surf. A: Physicochemi. Engin. Aspec. 2021, $610,5,125923$.

38. Monisha, P.; Dharshini, P.P.; Gomathi, S.S.; Pushpanathan, K. Ferro to super-paramagnetic transition: Outcome of $\mathrm{Ni}$ doping in polyethylene glycol capped $\mathrm{CoFe}_{2} \mathrm{O}_{4}$ nanoparticles. J. Alloy. Comp. 2021, 856, 5, 157447.

39. Revathi, J.; JohnAbel, M.; Archana, V.; Sumithra, T.; Thiruneelakandan, R.; Prince, J.J. Synthesis and characterization of $\mathrm{CoFe}_{2} \mathrm{O}_{4}$ and $\mathrm{Ni}$-doped $\mathrm{CoFe}_{2} \mathrm{O}_{4}$ nanoparticles by chemical Co-precipitation technique for photo-degradation of organic dyestuffs under direct sunlight. 2020, 587, 15, 412136.

40. Mmelesi, O. K.; Masunga, N.; Kuvarega, A.; Nkambule, T.TI.; Mamba, B. B.; Kefenia, K.K. Photocatalytic, antimicrobial activity and toxicity in water treatment. J. Mate. Scien. Semicond. Proce. 2021, 123, 1, 105523. 